\title{
Joint analysis of infrasound and seismic signals by cross wavelet transform: detection of Mt. Etna explosive activity
}

\author{
A. Cannata, P. Montalto, and D. Patanè \\ Istituto Nazionale di Geofisica e Vulcanologia, Osservatorio Etneo - Sezione di Catania, Piazza Roma 2, 95123 Catania, Italy
}

Correspondence to: A. Cannata (andrea.cannata@ct.ingv.it)

Received: 13 September 2012 - Published in Nat. Hazards Earth Syst. Sci. Discuss.: -

Revised: 11 February 2013 - Accepted: 12 February 2013 - Published: 26 June 2013

\begin{abstract}
The prompt detection of explosive volcanic activity is crucial since this kind of activity can release copious amounts of volcanic ash and gases into the atmosphere, causing severe dangers to aviation. In this work, we show how the joint analysis of seismic and infrasonic data by wavelet transform coherence (WTC) can be useful to detect explosive activity, significantly enhancing its recognition that is normally done by video cameras and thermal sensors. Indeed, the efficiency of these sensors can be reduced (or inhibited) in the case of poor visibility due to clouds or gas plumes. In particular, we calculated the root mean square (RMS) of seismic and infrasonic signals recorded at Mt. Etna during 2011. This interval was characterised by several episodes of lava fountains, accompanied by lava effusion, and minor strombolian activities. WTC analysis showed significantly high values of coherence between seismic and infrasonic RMS during explosive activity, with infrasonic and seismic series in phase with each other, hence proving to be sensitive to both weak and strong explosive activity. The WTC capability of automatically detecting explosive activity was compared with the potential of detection methods based on fixed thresholds of seismic and infrasonic RMS. Finally, we also calculated the cross correlation function between seismic and infrasonic signals, which showed that the wave types causing such seismo-acoustic relationship are mainly incident seismic and infrasonic waves, likely with a common source.
\end{abstract}

\section{Introduction}

As stated by Tilling (2008), the risk to humankind posed by volcano hazards will increase over time since, although the number of volcanoes that are active per year varies a little, global population and air traffic continue to grow. To mitigate the risk associated with the volcano hazard, monitoring activities play a fundamental role. It was shown how monitoring based on a single parameter can be unreliable. The most promising approach to detect and investigate the volcanic unrest phases is the joint monitoring of several different parameters (e.g. Scarpa and Gasparini, 1996; McNutt et al., 2000; Tilling, 2008).

Focusing on Mt. Etna volcano, the kinds of hazard that need to be taken into account are associated with both effusive (lava flow invasion; e.g. Andronico and Lodato, 2005) and explosive activities (ash clouds/fallout and pyroclastic flows; e.g. Scollo et al., 2009; Behncke, 2009). In particular, a fairly wide spectrum of volcanic activities has taken place during the last few years. On 13 May 2008, an eruption started at Mt. Etna from an eruptive fissure, opened in the eastern flank of Mt. Etna, and was characterised by both effusive and explosive activity (e.g. Cannata et al., 2011). After the end of this eruption on 6 July 2009, the activity resumed in 2010 with minor explosive episodes from southeast crater (SEC; in April), Bocca Nuova (BN; in August) and north-east crater (NEC; in November) (see inset in Fig. 1 for a digital elevation model of the summit area; Andronico et al., 2013). In 2011 such explosive activity culminated in a series of 18 paroxysms (lava fountains) at a new crater, opened at the base of SEC and named "new SEC" owing to its vicinity to the older crater (see inset in Fig. 1). Each lava fountain showed an initial strombolian phase, accompanied by lava effusion emplacing on the upper Valle del Bove (e.g. Cassisi et al., 2012; Fig. 1). The prompt detection of this kind of activity is crucial, because lava fountains release copious amounts of volcanic ash and gases into the atmosphere, which may threaten aviation (e.g. Scollo et al., 2009). Together with these 18 lava fountains, another 2 significant 


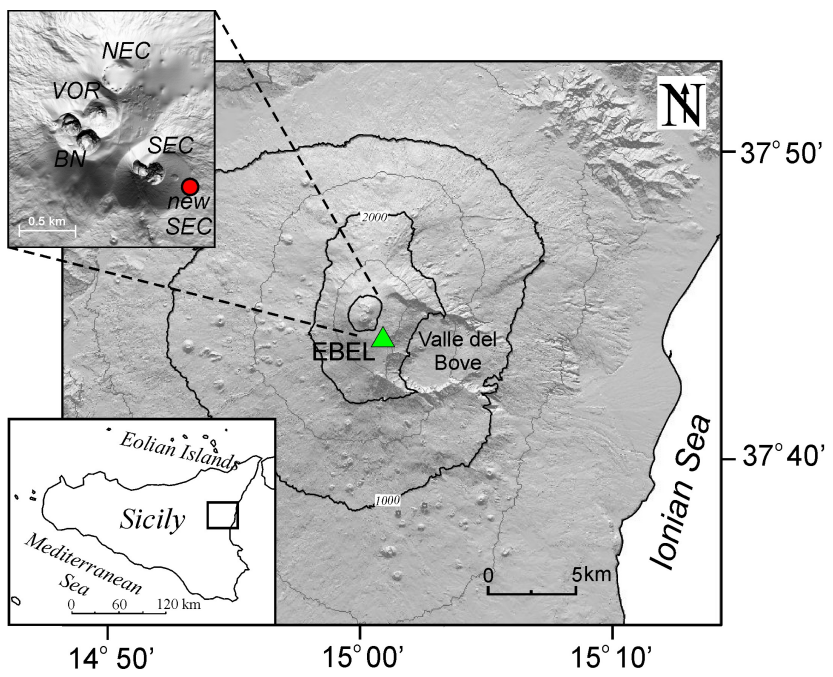

Fig. 1. Digital elevation map of Mt. Etna showing the location of EBEL infrasonic-seismic station (green triangle). The digital elevation model in the upper left corner shows the distribution of the summit craters (VOR: Voragine, BN: Bocca Nuova, SEC: southeast crater, NEC: north-east crater) and the new SEC, indicated by the red dot.

eruptive episodes also occurred at the new SEC and BN during 2011. During the first days of January, the former was characterised by strombolian activity, preceding the first lava fountain by 10 days. BN was also affected by strombolian activity, which mainly took place from 11 to 17 July.

In this paper, we show how the joint comparison of seismic and infrasonic data by wavelet transform coherence can be useful to detect explosive activity.

\section{Data}

We used seismic and infrasound signals recorded during 2011 by EBEL station, located $1.7 \mathrm{~km}$ away from the centre of the summit area and $\sim 1 \mathrm{~km}$ from the new SEC (Fig. 1). The seismic signal was recorded by broadband (40 s cut-off period), three-component Trillium seismometers (Nanometrics), acquiring in real time at a sampling rate of $100 \mathrm{~Hz}$. The infrasound signal was recorded at a sampling rate of $50 \mathrm{~Hz}$ by a GRASS 40AN microphone with a flat response with sensitivity of $50 \mathrm{mV} \mathrm{Pa}^{-1}$ in the frequency range $0.3-$ $20000 \mathrm{~Hz}$. The root mean square (RMS) of both seismic and infrasonic signals, filtered in the band $0.5-5.5 \mathrm{~Hz}$, was calculated. Such frequency band was chosen because it contains most of the energy of both seismic and infrasonic signals originating from the Mt. Etna activity (e.g. Cannata et al., 2009; Montalto et al., 2010; Cassisi et al., 2012). The window length, used to obtain the RMS, was equal to 1 and $10 \mathrm{~min}$, depending on the considered time series duration: if 1-yrlong signal is considered, 10-min windows are used, while, if a few-day-long signal is analysed, then 1-min windows.

\subsection{Wavelet transform coherence}

For the time-frequency analysis of signals, short-time Fourier transform (STFT) and continuous wavelet transform (CWT) techniques are commonly applied (Daubechies, 1990). STFT provides time-frequency representation by transforming short windows of data. In this case, a Fourier spectrum is computed over time on a fixed-size window shifted along the time axis. STFT has a drawback: a fixed-size moving window limits the detection of cycles at wavelengths that are longer than the windows itself, and nonstationarity in short wavelength is smoothed (e.g. Gershenfeld, 1999; Prokoph and Patterson, 2004). The CWT solves this problem, because it uses wide windows at low frequencies and narrow windows at high frequencies, thus providing a multi-scale representation of the signal. One particular wavelet, used for time series feature extraction, is the Morlet wavelet, which provides a Gaussian modulation of the time-scale plane (Grinsted et al., 2004).

To perform a joint investigation of both seismic and infrasonic RMS, the wavelet transform coherence (WTC) was calculated (Torrence and Compo, 1998). This technique has been used to compare time series in seismology (e.g. Cannata et al., 2010a), as well as in other disciplines such as meteorology (e.g. Jevrejeva et al., 2003), epidemiology (e.g. Yang et al., 2008) and astrophysics (e.g. Donner and Thiel, 2007). While correlation, also called Pearson's correlation, is a measure of the degree of similarity between two signals, coherence provides the correlation between two signals at a certain frequency $\lambda$. Extension of coherence measure between two time series $\mathrm{X}$ and $\mathrm{Y}$ to a wavelet domain leads to a definition of the WTC that evaluates how coherent the two time series in time-frequency domain are, normalized in the range 0-1 (Jevrejeva et al., 2003). Commonly, power spectra of geophysical time series are characterised by increasing power at lower frequencies and show many distinctive red noise features. Following previous studies (e.g. Jevrejeva et al., 2003; Grinsted et al., 2004; Cannata et al., 2010b), a $5 \%$ statistical significance level against red noise is considered in this study. The significance level is empirically obtained through Monte Carlo simulations (e.g. Torrence and Compo,1998; Grinsted et al., 2004). WTC can also provide information about phase difference between time series (e.g. Torrence and Compo,1998; Grinsted et al., 2004).

When comparing time series, the advantage of using WTC instead of the simple cross correlation is the ability to provide information not only in the time but also in the frequency domain at different observation scales. This means that by WTC we can acquire information about both the intervals and the frequencies at which two given time series are similar. Indeed, as stated by Grinsted et al. (2004), the definition of WTC closely resembles the definition of traditional correlation coefficient, and thus the wavelet coherence can be considered as a localized correlation coefficient in timefrequency space. 


\subsection{Mt. Etna 2011 case study}

During the last decade, many papers have shown that seismoacoustic studies can provide useful information to investigate the volcano dynamics (e.g. Hagerty et al., 2000; Ripepe et al., 2001; Johnson and Aster, 2005; Petersen and McNutt, 2007; Matoza et al., 2009). Notably, it was demonstrated how, in particular conditions (e.g. seismo-acoustic signals recorded by stations very close to the eruptive/degassing vents, intense explosive activity, very low level seismo-acoustic noise), seismic and acoustic signals, as well as their amplitude temporal patterns, are closely related to each other (e.g. Ripepe et al., 1996, 2001, 2010; Ichihara et al., 2012). For instance, Ripepe et al. (2001), performing a seismo-acoustic experiment at Mt. Etna during strombolian activity, observed that at short distances from the eruptive vents (a few hundreds of meters) volcanic tremor showed amplitude modulations that correlated well with infrasound amplitude. In this case, it was also noted how volcanic tremor at such short distances from the source shows rectilinearity peaks, well-correlated with infrasonic pulses, suggesting a wave field mainly made up of $P$ waves.

Thus, in order to further investigate such seismo-acoustic relationship at Mt. Etna, WTC was applied on RMS time series of infrasonic and seismic signals recorded at EBEL station throughout 2011 by using 10-min-long time windows with no overlap (Fig. 2). As shown in Fig. 2c, the time intervals with the highest values of coherence (statistically significant) at wide period range, characterised by peaks in both the RMS time series, coincide with explosive activity (mostly with lava fountain activities, indicated by red vertical arrows in Fig. 2a and b). Further, for each 10-min window we extracted and averaged the coherence values at period of 1602560 min (falling in the yellow dashed rectangle in Fig. 2c). Variations in time of such average coherence values show a nearly perfect agreement between average coherence peaks and lava fountain occurrences (Fig. 2d). All the lava fountains are characterised by average coherence above 0.7 (in most cases above 0.9). Also the episode of strombolian activity at new SEC at the beginning of January is accompanied by coherence values above 0.7 .

Successively, two intervals were analysed in detail: (i) 24 January and (ii) 6-9 October. As mentioned in Sect. 1, the former was characterised by strombolian activity from the new SEC, indicated in the infrasonic helicorder by infrasonic events and in the seismic signal by both transients (called explosion-quakes by some authors; e.g. Wassermann, 2009) and increase in volcanic tremor amplitude (Fig. 3). During the night between 2 and 3 January, the intensification of the strombolian activity was suggested by further increases in rate and amplitude of infrasonic and seismic events and by an increase in volcanic tremor amplitude. RMS of seismic and infrasonic signals, filtered between 0.5 and $5.5 \mathrm{~Hz}$, was calculated by using 1-min-long time windows with no overlap, as well as the WTC between these RMS
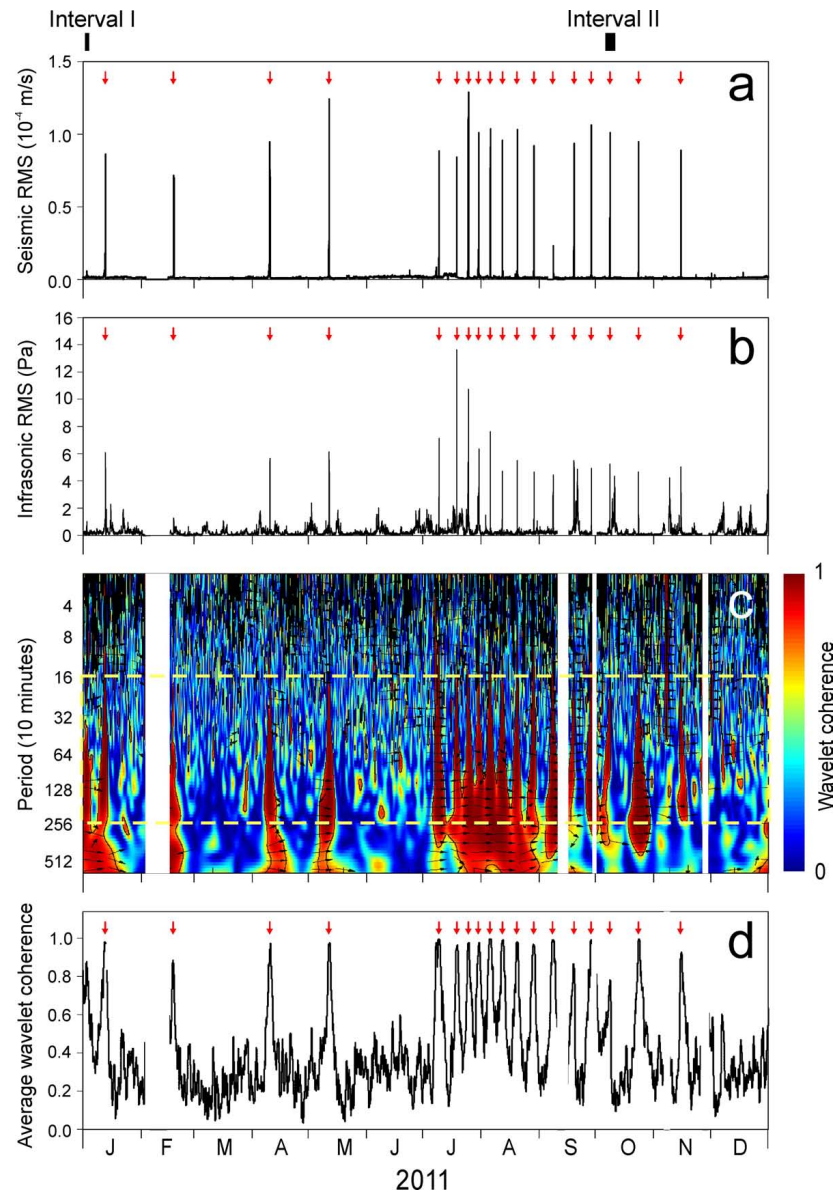

Fig. 2. (a) RMS velocity of the vertical component of the seismic signal at EBEL station calculated on 10-min-long windows filtered in the band $0.5-5.5 \mathrm{~Hz}$. (b) RMS pressure of the infrasonic signal recorded by EBEL station calculated on 10-min-long windows filtered in the band $0.5-5.5 \mathrm{~Hz}$. (c) Wavelet coherence between the time series in (a) and (b). The 5\% significance level against red noise is shown as a black contour. The black arrows indicate the phase difference between infrasonic and seismic RMS (a horizontal arrow pointing from left to right signifies in phase and an arrow pointing vertically upward means the first series lags the second one by $90^{\circ}$ ). (d) Variation in time of coherence calculated by averaging the values falling in the yellow dashed rectangle in (c). The black rectangles and the label "Interval I" and "Interval II", at the top of (a), indicate the time spans analysed in Figs. 3-6. The red vertical arrows in (a), (b), and (d) indicate the lava fountain occurrences. WTC was computed by Matlab toolbox provided by Grinsted et al. (2004). The white rectangle in (c) in February indicates a time span with no data.

time series (Fig. 4). While almost the whole considered interval shows many brief increases in coherence at short periods $(<16 \mathrm{~min})$, caused by the occurrence of seismo-acoustic events, only the time span during the intense strombolian activity phase was accompanied by significantly high values of coherence also at long periods $(>\sim 50 \mathrm{~min})$. Therefore, unlike mild strombolian activity, the intense one was 

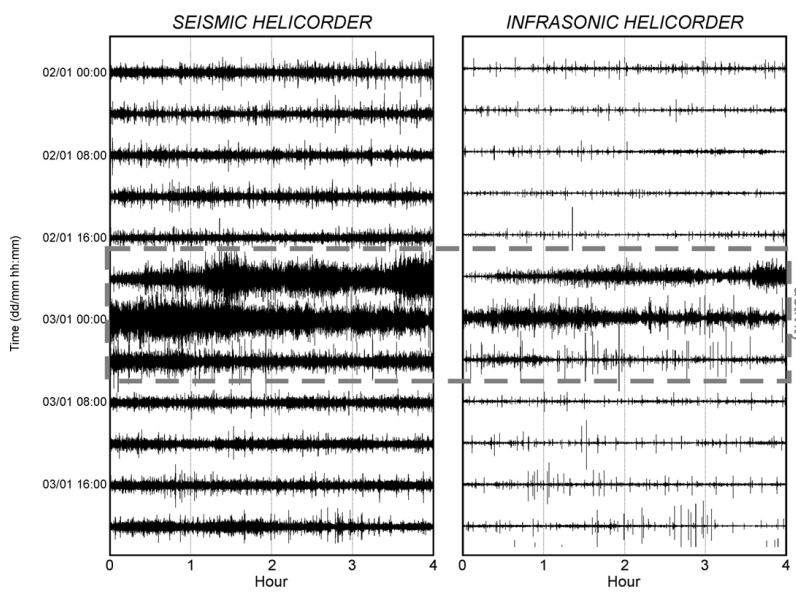

Fig. 3. Helicorder plots of seismic and infrasonic signals recorded from 2 to 3 January 2011 at EBEL station. The grey dashed rectangle indicates the time interval characterised by intense strombolian activity.

characterised by common seismic-infrasonic RMS patterns also at long periods of tens of $\mathrm{min} / \mathrm{h}$. In Fig. $4 \mathrm{c}$, the phase differences between the two time series are indicated with black arrows. In particular, a horizontal arrow pointing from left to right signifies in phase and an arrow pointing vertically upward means the first series lags the second one by $90^{\circ}$. The arrows indicate that the two time series are mostly in phase, namely that infrasonic amplitude increases correspond to seismic amplitude increases and vice versa. The coincidence between intensification of the strombolian activity and coherence increase is also confirmed by Fig. 4d, showing the average coherence obtained by values falling in the yellow dashed rectangle in Fig. 4c.

During the latter interval (6-9 October), a lava fountain, preceded and followed by strombolian activity phases, took place at the new SEC. Similarly to what was observed in the former interval, the increase in explosivity was accompanied by an increase in both rate and amplitude of seismic and infrasonic events, as well as by an increase in volcanic tremor and infrasonic tremor amplitude (Fig. 5). Also in this case, both the WTC, calculated between seismic and infrasonic RMS (Fig. 6c), and the average coherence values (Fig. 6d) show significantly high values of coherence especially during the lava fountain phase, with the black arrows indicating that the two time series are mainly in phase. Similarly to the 2-3 January case, there are many brief coherence increases at periods shorter than $\sim 50 \mathrm{~min}$, mostly related to energetic seismo-acoustic events, even during intervals preceding and following both strombolian and lava fountaining activities. Conversely, the coherence increases at longer periods are almost exclusively obtained during the explosive activity. This confirms what was observed during the first analysed case; namely, the intense explosive activity is generally accompanied by significantly high values of coherence not only at short but also at long periods ( $>\sim 50 \mathrm{~min})$.
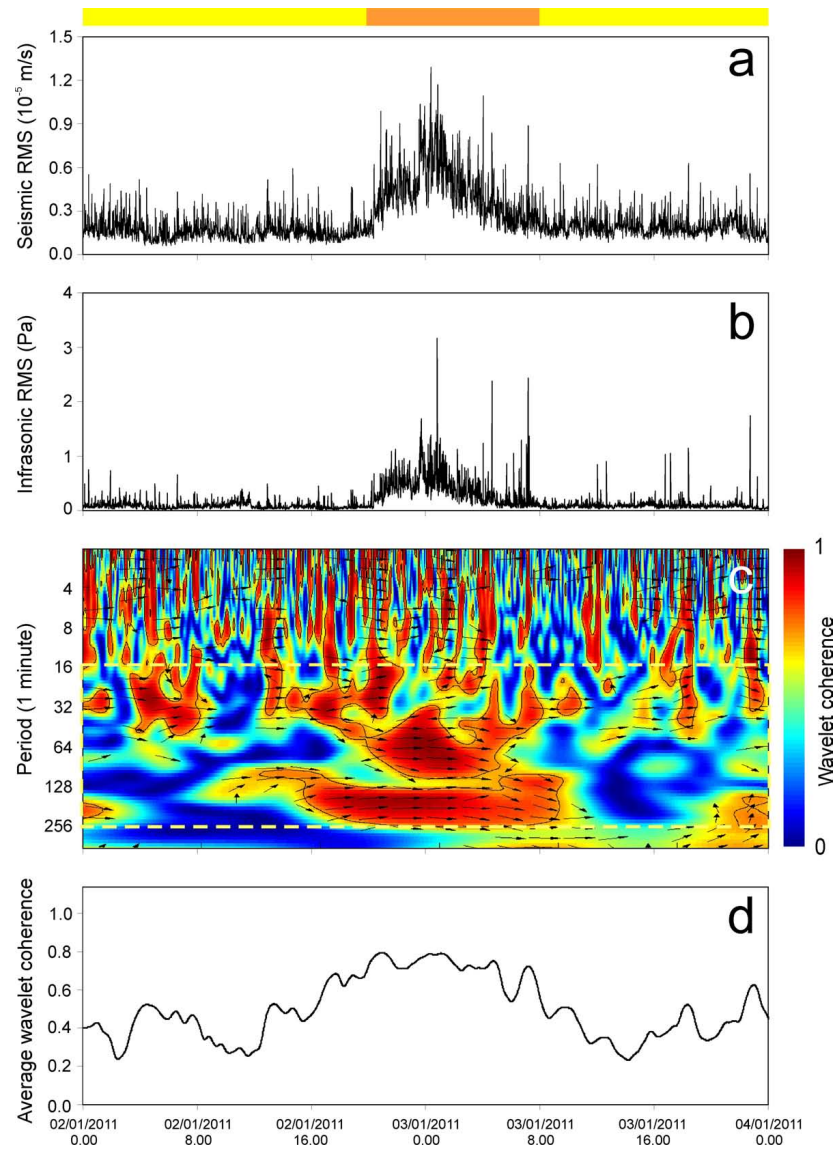

Fig. 4. (a) RMS velocity of the vertical component of the seismic signal at EBEL station calculated on 1-min-long windows filtered in the band $0.5-5.5 \mathrm{~Hz}$. (b) RMS pressure of the infrasonic signal recorded by EBEL station calculated on 1-min-long windows filtered in the band $0.5-5.5 \mathrm{~Hz}$. (c) WTC between the time series in (a) and (b). The 5\% significance level against red noise is shown as a black contour. The black arrows indicate the phase difference between infrasonic and seismic RMS (a horizontal arrow pointing from left to right signifies in phase and an arrow pointing vertically upward means the first series lags the second one by $90^{\circ}$ ). (d) Variation in time of coherence calculated by averaging the values falling in the yellow dashed rectangle in (c). The yellow and red rectangles at top of (a) indicate the intervals characterised by mild and intense strombolian activity, respectively. WTC was computed by Matlab toolbox provided by Grinsted et al. (2004).

\subsection{Investigation on detection threshold}

As highlighted in Sect. 2.2, the main eruptive activities during 2011 were accompanied by coherence values roughly above 0.7. In order to look for reliable values of coherence threshold, allowing detection of explosive activity, we performed the following analysis. Coherence threshold values were systematically changed in the range $0.5-1.0$, and for each value the true and false detections were counted (Fig. 7a). The total number of the considered episodes of explosive activity was 20 , comprising both the 18 lava fountains 

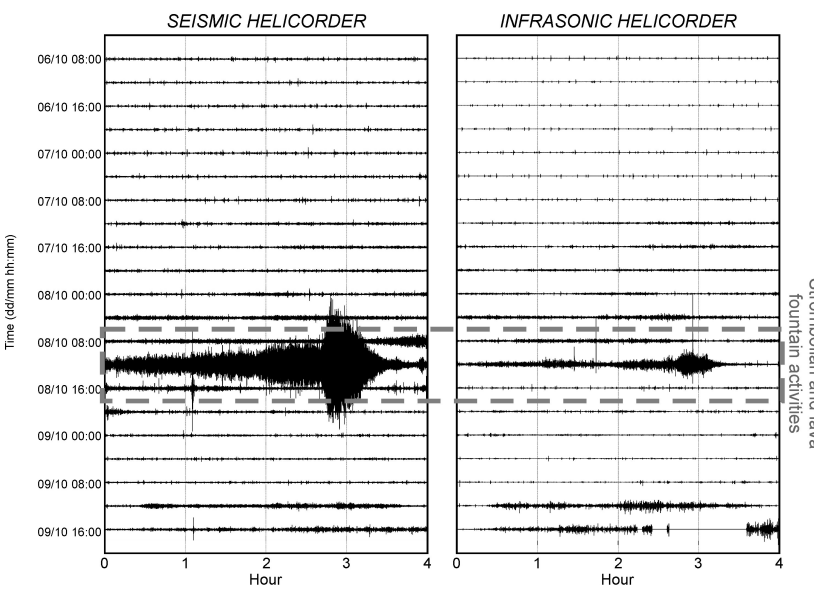

Fig. 5. Helicorder plots of seismic and infrasonic signals recorded from 6 to 9 October 2011 at EBEL station. The grey dashed rectangle indicates the time interval characterised by strombolian and lava fountain activities.

and the 2 episodes of strombolian activity at the new SEC and BN (see Sect. 1). Furthermore, for the sake of comparison, we also applied detection methods based on fixed thresholds of seismic and infrasonic RMS (see Alparone et al., 2007a) and reported the results in Fig. 7b and c, respectively.

Figure 7 shows that for all the three applied techniques the maximum number of true detections was 19. Indeed, the BN strombolian activity, taking place in July, was accompanied by such weak increases in both seismic and infrasonic RMS that its detection would have required very low thresholds. Then, we compared the portions of the plots (a), (b) and (c) corresponding to 19 true detections. The method based on a fixed threshold of infrasonic RMS proved to be affected by the highest number of false detections ( $>100)$. This is due to the fact that this kind of signal can be very noisy, especially if recorded at the summit of volcanoes (where EBEL station is located) with no barriers (such as trees) to dissipate the wind. On the other contrary, the methods based on thresholds of seismic RMS and on coherence were characterised by numbers of false detections ranging 5-35 and 2-25, respectively. Therefore, it is worth noting that the maximum number of true detections with the minimum number of false ones was obtained by the method based on a fixed threshold of coherence. In particular, a coherence threshold of 0.70 0.75 allows obtaining the best results in terms of maximum number of true detections (19) with the minimum number of false ones (2-5; see grey area in Fig. 7a).

\subsection{Analysis of seismo-acoustic relationship}

Ichihara et al. (2012) described a method that enables investigating the seismo-acoustic relationship. In particular, the graphical presentation of temporal variations in the cross correlation function between seismic and infrasonic envelopes allows seeing qualitative changes in eruptive activity, as well
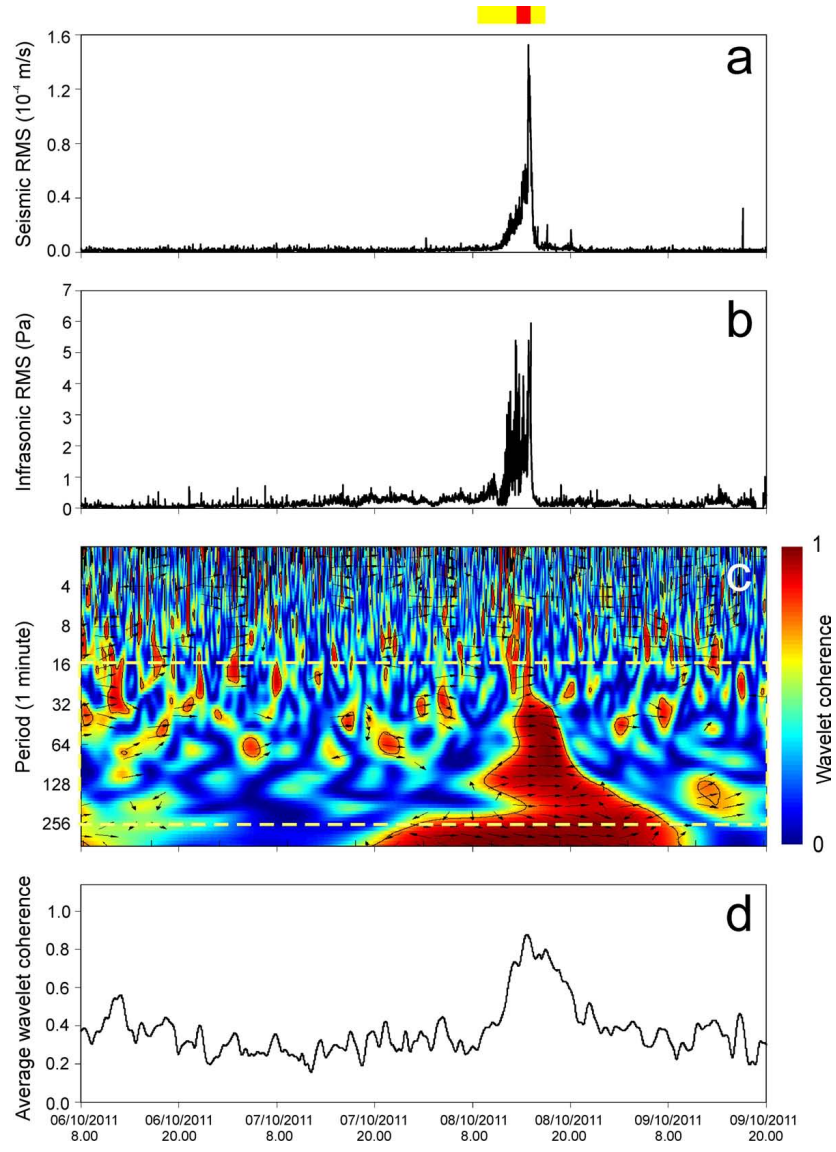

Fig. 6. (a) RMS velocity of the vertical component of the seismic signal at EBEL station calculated on 1-min-long windows filtered in the band $0.5-5.5 \mathrm{~Hz}$. (b) RMS pressure of the infrasonic signal recorded by EBEL station calculated on 1-min-long windows filtered in the band $0.5-5.5 \mathrm{~Hz}$. (c) WTC between the time series in (a) and (b). The 5\% significance level against red noise is shown as a black contour. The black arrows indicate the phase difference between infrasonic and seismic RMS (a horizontal arrow pointing from left to right signifies in phase and an arrow pointing vertically upward means the first series lags the second one by $90^{\circ}$ ). (d) Variation in time of coherence calculated by averaging the values falling in the yellow dashed rectangle in (c). The yellow and red rectangles at the top of (a) indicate the intervals characterised by strombolian and lava fountain activities, respectively. WTC was computed by Matlab toolbox provided by Grinsted et al. (2004).

as recognising the wave types causing such a seismo-acoustic relation. Indeed, assuming that the terms related to the wind noise are negligible, the abovementioned cross correlation function depends on three terms (Ichihara et al., 2012): (i) cross correlation term between incident seismic and infrasonic signals; (ii) autocorrelation term between the incident seismic waves and the pressure waves generated by these seismic waves; and (iii) autocorrelation term between incident pressure waves and the seismic waves due to this pressure waves. In order to distinguish which term is dominant, the seismo-acoustic lag, highlighted by the cross correlation 

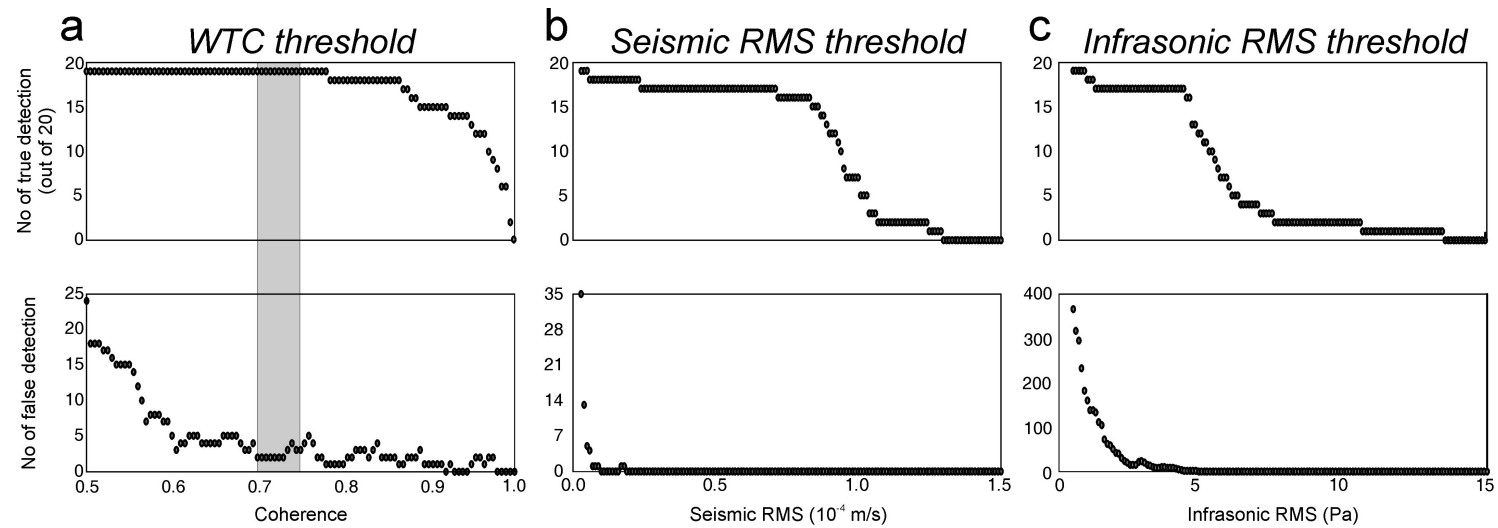

Fig. 7. (a) Number of true and false detections versus wavelet coherence threshold. (b) Number of true and false detections versus fixed seismic RMS threshold. (c) Number of true and false detections versus fixed infrasonic RMS threshold. The grey area in (a) highlights the range of coherence values chosen as the best thresholds.

plots, can be used. Indeed, if the cross correlation plot shows negative values of seismo-acoustic lag (namely seismic waves precede the acoustic ones), the seismo-acoustic relation is dominated by the first term, that is, by incident seismic and acoustic waves having a common source. Otherwise, if such lag has values $\geq 0$, the other two terms are dominant.

Thus, in order to pinpoint the wave types determining the seismic-infrasonic relationship, observed during explosive activity at Mt. Etna and highlighted in Sect. 2.2, the Ichihara et al. (2012) method was applied. The cross correlation function was calculated on 10-s-long moving windows, and the two explosive activity episodes analysed in detail in Sect. 2.2 were taken into account. In particular, in both cases we visualised cross correlation plots for $24 \mathrm{~h}$ : from 12:00 UTC on 2 January to 12:00 UTC on 3 January and from 00:00 UTC to 24:00 UTC on 8 October. The results, reported in Fig. 8, show that in both cases the cross correlation function is dominated by incident seismic and infrasonic waves likely having a common source, as suggested by the negative lag values. However, there are time spans (such as 20:00-21:00 UTC on 2 January and 14:00-15:00 UTC on 8 October) characterised by time lags roughly equal to 0 , and then dominated by the autocorrelation terms.

The fact that in most cases the observed seismo-acoustic lag is different from 0 has an important implication regarding the choice of the seismic and infrasonic signal windows. Indeed, if short (a few seconds) windows are preferred to make a comparison between seismic and infrasonic signals, such lags should be taken into account before extracting the windows. Assuming that the seismic and infrasonic sources are co-located, the theoretical lag values mainly depend on the distance source-station, as well as on the seismic and acoustic velocities. The relatively long signal window durations used in the above described examples ( 1 and 10 min for WTC and $10 \mathrm{~s}$ for cross correlation), together with the very short distance station-source $(\sim 1.0-1.7 \mathrm{~km}$ for new SEC and BN, respectively), allow neglecting eventual time lag between seismic and infrasonic signals.

\section{Discussion and conclusions}

The effectiveness of the joint seismic-infrasonic analysis has been demonstrated by several studies related or not to volcanoes. Concerning the "non-volcanic studies", joint seismic and infrasonic signals were used to characterise many phenomena such as mining or surface explosions (e.g. Chilo et al., 2006; Gibbons et al., 2007), atmospheric entry of a meteoroid (e.g. Le Pichon et al., 2008), earthquakes (e.g. Mutschlecner and Whitacker, 2005) and ocean noise (e.g. Barruol et al., 2006). On volcanoes the joint seismicinfrasonic analysis has been performed to obtain useful information. For instance, Ripepe and Braun (1994) and Petersen and McNutt (2007), by calculating the lag between seismic and infrasonic signals, obtained information on the depth of explosive sources at Stromboli and Shishaldin, respectively. Johnson and Aster (2005), studying the variability of the ratio between seismic and acoustic energies, made inferences about explosive dynamics inside the volcanic vents and conduits at Karymsky and Erebus. Matoza et al. (2009) performed finite difference simulation of the seismo-acoustic wave field to investigate the source mechanism of the repetitive long-period events at St. Helens. More recently, Ichihara et al. (2012) highlighted how temporal variations in cross correlation function between seismic and infrasonic signals can allow visually detecting changes in eruptive activity.

In this work, we demonstrated how a joint analysis of seismic and infrasonic data, performed by wavelet transform coherence, can be useful to detect explosive activity. The detection of this kind of activity is generally made by video cameras and thermal sensors (e.g. Spampinato et al., 2011), whose efficiency can be reduced (or inhibited) because of 

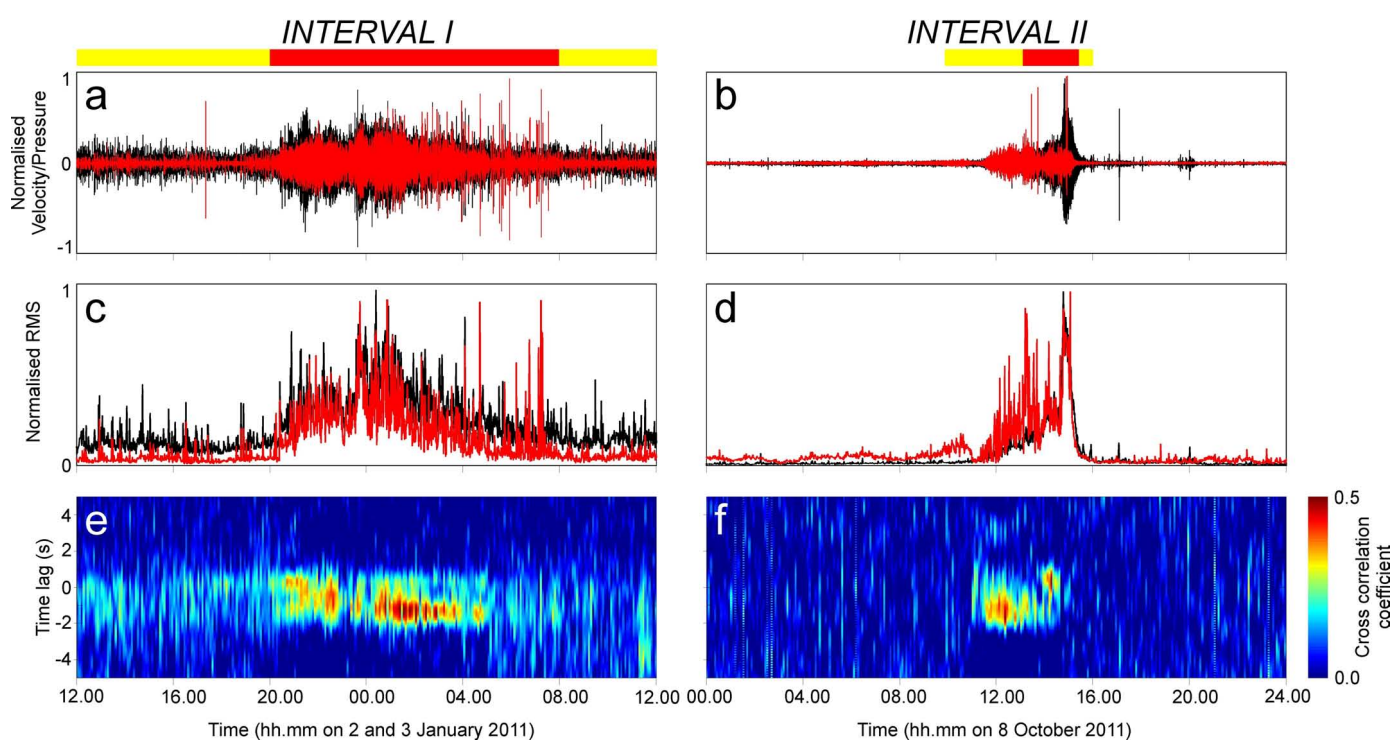

Fig. 8. (a,b) Infrasonic (red line) and seismic (black line) signals, (c, d) infrasonic (red line) and seismic (black line) RMS time series, and (e,f) corresponding cross correlation plots. (a), (c), and (e) refer to the time span from 12:00 UTC on 2 January to 12:00 UTC on 3 January, while (b),(d), and (f) refer to the time span from 00:00 UTC to 24:00 UTC on 8 October. The yellow and red rectangles at the top of (a) indicate the intervals characterised by mild and intense strombolian activity, respectively. The yellow and red rectangles at the top of (b) indicate the intervals characterised by strombolian and lava fountain activities, respectively. Negative and positive values of time lag in (e) and (f) signify that seismic signals precede and follow the infrasonic ones, respectively.

poor visibility caused by clouds or gas plumes. In this case, seismic and acoustic monitoring can be helpful. Indeed, explosive activity is generally accompanied by seismic transients (such as long period events, explosion-quakes) and increases in the amplitude of volcanic tremor, as observed both at Mt. Etna (e.g. Cannata et al., 2008) and at other worldwide active volcanoes (e.g. McNutt, 1994). Explosive volcanic activity is known to also generate acoustic waves in the infrasonic frequency range $(<20 \mathrm{~Hz}$; e.g. Arrowsmith et al., 2010). In particular, strombolian activity produces excess pressures recorded within a few kilometers of a vent, such as at Stromboli (Ripepe and Marchetti, 2002), Pacaya (Dalton et al., 2010), Fuego (Lyons et al., 2010), Tungurahua (Fee et al., 2010) and Mt. Etna (Cannata et al., 2009). However, there are some drawbacks in using seismic or infrasound recordings separately to detect explosive activity. Concerning the seismic signal, there are some cases when increases in seismic amplitude do not correspond to eruptive activity. For instance, the activation of deep tremor sources causes seismic amplitude increase without any observable variation of eruptive activity (Alparone et al., 2007b). Moreover, also banded tremor, a particular kind of tremor recorded in geothermal and volcanic areas, consists of cyclic increases in the amplitude of seismic signal generally unrelated to changes in eruptive activity (e.g. Cannata et al., 2010b). Likewise, increases in the amplitude of infrasound signals do not necessarily imply ongoing explosive activity. Indeed, although infrasound signals exhibit low atmospheric scattering/dissipation
(Ripepe et al., 2009), weather-dependent effects like wind noise are not easily filtered out.

The joint analysis of both seismic and infrasonic signals can overcome the aforementioned drawbacks of the single signal, leading to a reliable detection of ongoing explosive activity. WTC between seismic and infrasonic signals is sensitive to both weak and strong explosive activity, as shown by the two intervals analysed in detail: the first one was characterised by mild and intense strombolian activity (Figs. 3 and 4), while the second by strombolian and lava fountain activities (Figs. 5 and 6).

Some authors have shown that seismic and acoustic signals recorded in volcanic areas can sometimes be closely related to each other even when there is no eruptive activity (e.g. Ripepe et al., 1996, 2010). For instance, Ripepe et al. (2010) reported that infrasonic tremor at Villarica is characterised by discrete high amplitude bursts and is well correlated (0.93) with seismic tremor. However, this is not the case of Mt. Etna during 2011. Indeed, Patanè et al. (2013) demonstrated that volcanic tremor at Mt. Etna during 2011 is dominated by relatively deep sources $(\sim 1 \mathrm{~km}$ a.s.l.), not directly related to shallow phenomena coupled with the atmosphere. Only during explosive activity episodes did volcanic tremor sources become shallow and come close to the eruptive vents (Patanè et al., 2013). In confirmation of this, Fig. 2c and $d$ show that only intervals of explosive activity are characterised by significantly high seismic-infrasonic coherence at wide range of periods. 
In view of a future development of an automatic system, we extracted and averaged the wavelet coherence values falling in a certain period range, thus producing simple time series (Figs. 2d, 4d and 6d). Figure 7 demonstrates how the capacity of explosive activity detection by a method based on a coherence threshold is even slightly better than the ability of a method based on a fixed threshold of seismic RMS. The analyses performed in this work show that the application of a coherence threshold equal to $0.70-0.75$ allows a reliable automatic detection of explosive activity by using a single station equipped with both seismic and infrasonic sensors. In any case, similar to all the automatic detection systems of volcano activity changes, such a technique cannot be considered absolutely reliable. Indeed, as demonstrated by this study, the strombolian activity episode taking place at BN in July could not be detected. Moreover, we cannot exclude that in the future sustained degassing, with no explosive activity, will produce seismic and acoustic signals so closely related to overcome the coherence threshold of $0.70-0.75$, thus generating false detections.

Finally, it has also been shown how the WTC method can be considered complementary to the Ichihara et al. (2012) technique to investigate the seismo-acoustic relations. Indeed, while the former can be implemented to automatically detect explosive activity (by calculating the average coherence values and properly fixing a threshold) and provide information on the period range in which seismic and infrasonic amplitude patterns are related or not, the latter is very useful to characterise the wave types determining such a seismo-acoustic relation.

Acknowledgements. Crosswavelet and wavelet coherence software were kindly provided by A. Grinsted. We are grateful to Maurizio Ripepe and an anonymous reviewer for their useful suggestions that greatly improved the paper. We thank Stephen Conway for revising and improving the English text of this manuscript.

Edited by: A. Costa

Reviewed by: two anonymous referees

\section{References}

Alparone, S., Andronico, D., Sgroi, T., Ferrari, F., Lodato, L., and Reitano, D.: Alert system to mitigate tephra fallout hazards at Mt. Etna Volcano, Italy, Nat. Hazards 43, 333-350, 2007a.

Alparone, S., Cannata, A., and Gresta, S.: Time variation of spectral and wavefield features of volcanic tremor at Mt. Etna (JanuaryJune 1999), J. Volcanol. Geoth. Res., 161, 318-332, 2007b.

Andronico, D. and Lodato, L.: Effusive activity at Mount Etna volcano (Italy) during the 20th century: a contribution to volcanic hazard assessment, Nat. Hazards, 36, 407-443, 2005.

Andronico, D., Lo Castro, M. D., Sciotto, M., and Spina, L.: The 2010 ash emissions at the summit craters of Mt Etna: Relationship with seismo-acoustic signals, J. Geophys. Res., doi:10.1029/2012JB009895, in press, 2013.
Arrowsmith, S., Johnson, J., Drob, D., and Hedlin, M.: The Seismo-Acoustic Wavefield: A new paradigm in studying geophysical phenomena, Rev. Geophys., 48, RG4003, doi:10.1029/2010RG000335, 2010.

Barruol, G., Reymond, D., Fontaine, F. R., Hyvernaud, O., Maurer, V., and Maa-maatuaiahutapu, K.: Characterizing swells in the southern Pacific from seismic and infrasonic noise analyses, Geophys. J. Int., 164, 516-542, 2006.

Behncke, B.: Hazards from pyroclastic density currents at Mt. Etna (Italy), J. Volcanol. Geoth. Res., 180, 148-160, 2009.

Cannata, A., Catania, A., Alparone, S., and Gresta, S.: Volcanic tremor at Mt. Etna: inferences on magma dynamics during effusive and explosive activity, J. Volcanol. Geoth. Res., 178, 19-31, 2008.

Cannata, A., Montalto, P., Privitera, E., Russo, G., and Gresta, S.: Tracking eruptive phenomena by infrasound: May 13, 2008 eruption at Mt. Etna, Geophys. Res. Lett., 36, L05304, doi:10.1029/2008GL036738, 2009.

Cannata, A., Giudice, G., Gurrieri, S., Montalto, P., Alparone, S., Di Grazia, G., Favara, R., and Gresta, S.: Relationship between soil CO2 flux and volcanic tremor at Mt. Etna: implications for magma dynamics, Environ. Earth Sci., 61, 477-489, doi:10.1007/s12665-009-0359-z, 2010a.

Cannata, A., Di Grazia, G., Montalto, P., Ferrari, F., Nunnari, G., Patanè, D., and Privitera, E.: New insights into banded tremor from the 2008-2009 Mt. Etna eruption, J. Geophys. Res., 115, B12318, doi:10.1029/2009JB007120, 2010b.

Cannata, A., Sciotto, M., Spampinato, L., and Spina, L.: Insights into explosive activity at eruptive fissure closely-spaced vents by infrasound signals: example of Mt. Etna 2008 eruption, J. Volcanol. Geotherm. Res., 208, 1-11, 2011.

Cassisi, C., Aliotta, M., Cannata, A., Montalto, P., Patanè, D., Pulvirenti, A., and Spampinato, L.: Motif Discovery on Seismic Amplitude Time Series: The Case Study of Mt Etna 2011 Eruptive Activity, Pure Appl. Geophys., doi:10.1007/s00024-0120560-y, online first, 2012.

Chilo, J., Jabor, A., Liszka, L., Eide, A. J., Lindblad, T., and Persson, L.: Infrasonic and Seismic Signals from Earthquake and Explosions in Arequipa, Perú, Western Pacific Geophysics Meeting, 24-27 July 2006, KTH, Physics, Beijing China, QC 20101110 , 2006.

Dalton, M. P., Waite, G. P., Watson, I. M., and Nadeau, P. A.: Multiparameter quantification of gas release during weak Strombolian eruptions at Pacaya Volcano, Guatemala, Geophys. Res. Lett., 37, L09303, doi:10.1029/2010GL042617, 2010.

Daubechies, I.: The wavelet transform time-frequency localization and signal analysis, IEEE Trans. Inform. Theory, 36, 961-1004, 1990.

Donner, R. and Thiel, M.: Scale-resolved phase coherence analysis of hemispheric sunspot activity: a new look at the north-south asymmetry, Astron. Astrophys., 475, L33-L36, doi:10.1051/0004-6361:20078672, 2007.

Fee, D., Garces, M., and Steffke, A.: Infrasound from Tungurahua Volcano 2006-2008: Strombolian to Plinian eruptive activity, J. Volcanol. Geothm. Res., 193, 67-81, doi:10.1016/j.jvolgeores.2010.03.006, 2010.

Gershenfeld, N.: The Nature of Mathematical Modeling, Cambridge University Press, Cambridge, UK, 1999. 
Gibbons, S. J., Ringdal, F., and Kvaerna, T.: Joint seismic-infrasonic processing of recordings from a repeating source of atmospheric explosions, J. Acoust. Soc. Am., 122, 158-164, 2007.

Grinsted, A., Moore, J. C., and Jevrejeva, S.: Application of the cross wavelet transform and wavelet coherence to geophysical time series, Nonlin. Processes Geophys., 11, 561-566, doi:10.5194/npg-11-561-2004, 2004.

Hagerty, M. T., Schwartz, S. Y., Garcés, M. A., and Protti, M.: Analysis of seismic and acoustic observations at Arenal volcano, Costa Rica, 1995-1997, J. Volcanol. Geoth. Res., 101, 27-65, doi:10.1016/S0377-0273(00)00162-1, 2000.

Ichihara, M., Takeo, M., Yokoo, A., Oikawa, J., and Ohminato, T.: Monitoring volcanic activity using correlation patterns between infrasound and ground motion, Geophys. Res. Lett., 39, L04304, doi:10.1029/2011GL050542, 2012.

Jevrejeva, S., Moore, J. C., and Grinsted, A.: Influence of the Arctic Oscillation and El Nino-Southern Oscillation (ENSO) on ice conditions in the Baltic Sea: the wavelet approach, J. Geophys. Res., 108, 4677, doi:10.1029/2003JD003417, 2003.

Johnson, J. B. and Aster, R. C.: Relative partitioning of acoustic and seismic energy during Strombolian eruptions, J. Volcanol. Geoth. Res., 148, 334-354, doi:10.1016/j.jvolgeores.2005.05.002, 2005.

Le Pichon, A., Antier, K., Cansi, Y., Hernandez, B., Minaya, E., Burgoa, B., Drob, D., Evers, L. G., and Vaubaillon, J.: Evidence for a meteoritic origin of the September 15, 2007, Carancas crater, Meteoritics and Planetary Science, 43, 1797-1809, 2008.

Lyons, J. J., Waite, G. P., Rose, W. I., and Chigna, G.: Patterns in open vent, strombolian behavior at Fuego volcano, Guatemala (2005-2007), B. Volcanol., 72, 1-15, 2010.

Matoza, R. S., Garcés, M. A., Chouet, B. A., D’Auria, L., Hedlin, H., De Grooth-Hedlin, C., and Waite, G. P.: The source of infrasound associated with long-period events at Mount St. Helens, J. Geophys. Res., 114, B04305, doi:10.1029/2008JB006128, 2009.

McNutt, S. R.: Volcanic Tremor Amplitude Correlated with Eruption Explosivity and its Potential Use in Determining Ash Hazards to Aviation, US Geol. Surv. Prof. Paper, 2047, 377-385, 1994.

McNutt, S. R., Rymer, H., and Stix, J.: Synthesis of Volcano Monitoring, in: Encyclopedia of Volcanoes, edited by: Sigurdsson, H., Houghton, B., McNutt, S. R., Rymer, H., and Stix, J., Academic Press, San Diego CA, 1167-1185, 2000.

Montalto, P., Cannata, A., Privitera, E., Gresta, S., Nunnari, G., and Patanè, D.: Towards an automatic monitoring system of infrasonic events at Mt. Etna: strategies for source location and modelling, Pure Appl. Geophys., 167, 1215-1231, doi:10.1007/s00024-010-0051-y, 2010.

Mutschlecner, J. P. and Whitacker, R. W.: Infrasound from earthquakes, J. Geophys. Res., 110, D01108, doi:10.1029/2004JD005067, 2005.

Patanè, D., Aiuppa, A., Aloisi, M., Behncke, B., Cannata, A., Coltelli, M., Di Grazia, G., Gambino, S., Gurrieri, S., Mattia, M., and Salerno, G.: Insights into the cyclic eruptive behavior of Mount Etna during 2011: geophysical and geochemical constraints, J. Geophys. Res., submitted, 2013.
Petersen, T. and McNutt, S. R.: Seismo-acoustic signals associated with degassing explosions recorded at Shishaldin volcano, Alaska, 2003-2004, B. Volcanol., 69, 527-536, doi:10.1007/s00445-006-0088-z, 2007.

Prokoph, A. and Patterson, R. T.: Application of wavelet and regression analysis in assessing temporal and geographic climate variability: Eastern Ontario, Canada as a case study, Atmos. Ocean, 42, 201-212, 2004.

Ripepe, M. and Braun, T.: Air-wave phases in strombolian explosion quake seismograms: a possible indicator for the magma level?, Acta Vulcanologica, 5, 201-206, 1994.

Ripepe, M. and Marchetti, E.: Array tracking of infrasonic sources at Stromboli volcano, Geophys. Res. Lett., 29, 2076, doi:10.1029/2002GL015452, 2002.

Ripepe, M., Poggi, P., Braun, T., and Gordeev, E.: Infrasonic waves and volcanic tremor at Stromboli, Geophys. Res. Lett., 23, 181184, doi:10.1029/95GL03662, 1996.

Ripepe, M., Coltelli, M., Privitera, E., Gresta, S., Moretti, M., and Piccinini, D.: Seismic and infrasonic evidences for an impulsive source of the shallow volcanic tremor at Mt. Etna, Italy, Geophys. Res. Lett., 28, 1071-1074, 2001.

Ripepe, M., Delle Donne, D., Lacanna, G., Marchetti, E., and Ulivieri, G.: The onset of the 2007 Stromboli effusive eruption recorded by an integrated geophysical network, J. Volcanol. Geoth. Res., 182, 131-136, doi:10.1016/j.jvolgeores.2009.02.011, 2009.

Ripepe, M., Marchetti, E., Bonadonna, C., Harris, A. J. L., Pioli, L., and Ulivieri, G.: Monochromatic infrasonic tremor driven by persistent degassing and convection at Villarrica Volcano, Chile, Geophys. Res. Lett., 37, L15303, doi:10.1029/2010GL043516, 2010.

Scarpa, R. and Gasparini, P.: A review of volcano geophysics and volcano-monitoring methods, in: Monitoring and mitigation of volcano hazards, edited by: Scarpa, R. and Tilling, R. I., Springer, 3-22, 1996.

Scollo, S., Prestifilippo, M., Spata, G., D’Agostino, M., and Coltelli, M.: Monitoring and forecasting Etna volcanic plumes, Nat. Hazards Earth Syst. Sci., 9, 1573-1585, doi:10.5194/nhess-9-15732009, 2009.

Spampinato, L., Calvari, S., Oppenheimer, C., and Boschi, E.: Volcano surveillance using infrared cameras, Earth Sci. Rev., 106, 63-91, doi:10.1016/j.earscirev.2011.01.003, 2011.

Tilling, R. I.: The critical role of volcano monitoring in risk reduction, Adv. Geosci., 14, 3-11, 2008, http://www.adv-geosci.net/14/3/2008/.

Torrence, C. and Compo, G.P.: A practical guide to Wavelet Analysis, B. Am. Meteorol. Soc., 79, 61-78, 1998.

Yang, L., Wong, C. M., Lau, E. H. Y., Chan, K. P., Ou, C. Q., and Peiris, J. S. M.: Synchrony of Clinical and Laboratory Surveillance for Influenza in Hong Kong, PLoS ONE, 3, e1399, doi:10.1371/journal.pone.0001399, 2008.

Wassermann, J.: Volcano Seismology, in: New manual of seismological observatory practice, edited by: Bormann, P., IASPEI, chapter 13, 42 pp., 2009. 